\title{
ESTUDOS SÔBRE RESERVATÓRIOS E VETORES SILVESTRES DO TRYPANOSOMA CRUZI. XVII. CONTRIBUIÇÃO PARA O ESTUDO DOS FOCOS NATURAIS DA TRIPANOSSOMOSE AMERICANA, COM ESPECIAL REFERÊNCIA À REGIÃO NORDESTE DO ESTADO DE SÃO PAULO, BRASIL *
}

\author{
M. P. BARRETTO
}

\begin{abstract}
Depois de acentuar que a tripanossomose americana é uma zoonose do tipo anfixenose, bem enquadrável no conceito de PAVLOVSKY de infeccão com jocos naturais, o Autor analisa o problema da multiplicidade e diversidade dêstes jocos que são devidas ao grande número de hospedeiros e vetores naturais com hábitos variados. Descreve, em seguida, alguns focos naturais mais frequientes e importantes, observados na região nordeste do Estado de São Paulo e áreas limitrofes do Estado de Minas Gerais, focos êstes constituílos por buracos $e$ cavidades no solo, ocos e anfractuosidades em troncos de árvores, tufos de vegetação herbácea, touceiras de piteira e copa de palmeiras, onde triatomíneos $e$ mamiferos convivem.
\end{abstract}

A tripanossomose americana, segundo tudo indica, era, primitivamente, uma enzootia, afetando exclusivamente animais siivestres e sendo transmitida por triatomineos de hábitos silvestres. Em algumas áreas do Continente Americano esta situação ainda persiste. Em outras, porém, o parasita foi transportado para nichos artituciais e passou a infectar o homem e os animais domésticos suscetiveis, em particular o cão e o gato, e a ser transmitido, agora, por triatomineos domiciliados.

Dada a grande suscetibilidade do homem e dêstes animais domésticos e em virtude da abundante proliferação de triatomíneos sinantrópicos, a infecção humana disseminou-se e o ciclo doméstico do parasita passou a assumir extraordinária importância. Não admira, pois, que a atenção dos pesquisadores se tenha concentrado na infecção nos ecótopos artificiais, com a descoberta de número cada vez maior de casos humanos da doença, à medida que os método $_{S}$ de diagnóstico foram sendo aperfeiçoados. Por outro lado, uma vez estabelecido o ciclo doméstico, os animais silves- tres podem deixar de constituir elos essenciais na cadeia epidemiológica. Êstes dois fatos fizeram com que, ro passado, se desse menor importância ao estudo do ciclo silvestre do parasita.

Investigações levadas a efeito, principalmente no decorrer dos últimos decênios, vêm, contudo, pondo em evidência a importância cada vez maior que assume a enzootia de animais silvestres, mesmo em área onde a infecção adquiriu caráter eminentemente domiciliário.

Hoje sabe-se perfeitamente que a tripanossomose americana é uma zoonose do tipo anfixenose, bem enquadrável na "doutrina da nidalidade" de ?PAVLOVSKY (33), isto é, no conceito de infecção com focos naturais (BARRETTO, 7) .

Os focos naturais da doença de Chagas constituem unidades ecológicas, integradas por ecótoros ou nichos mais ou menos bem definidos, nas quais vamos encontrar uma biccenose representada, em adição a componentes indiferentes ou irrelevantes, por mamíferos silvestres que albergam o Trypanosoma cruzi e que servem de fonte de

(*) Trabalho do Departamento de Parasitologia da Faculdade de Medicina de Ribcirão Prêto realizado, em parte, com auxílio financeiro da Fundação de Amparo à Pesquisa do Estado de Sáo Paulo e do Consêlho Nacional de Pesquisas. 
alimentação para triatomíneos silvestres, os quais se infectam e transmitem o parasita para outros mamíferos suscetíveis. Nestas circunstâncias, a transmissão regular e continuada do parasita é assegurada, independentemente da presença do homem, e esta situação pode perdurar por período indefinido, desde que o balanço ecológico não seja temporária ou definitivamente rompido, isto é, desde que os elementos essenciais da biocenose e as condições do meio permaneçam intatas.

Como sucede com outras zoonoses, os focos naturais da tripanossomose americana são variados. Isto se deve, de um lado, à grande variedade de mamíferos de hábitoss diversos que servem de hospedeiros, e, de outro lado, à multiplicidade e ubiqüidade de triatomíneos vectores, muitos dos quais euritopos, isto é, pouco exigentes quanto às condições ambientais, e quase todos eurítrofos, isto é, relativamente indiferentes quanto aos hospedeiros que lhes fornecem sangue.

Reconhecido o caráter zoonósico da tripanossomose americana, desde os primeiros trabalhos de CHAGAS $(17,18)$ vários pesquisadores, em diferentes épocas e em diversos países da América, têm procurado a infecção pelo $T$. cruzi em uma grande variedade de animais silvestres. Em conseqüência destas pesquisas descobriram-se flagelados idênticos ou semelhantes ao parasita humano em cêrca de uma centena de espécies ou subespécies de mamiferos silvestres $(2,3,4,5,11,12,13,16,17$, $18,20,21,22,23,31,36,37$ ) .

Quanto à identificação dêstes flagelados, fugiria aos moldes da presente exposição uma análise pormenorizada do problema que já foi objeto de recentes trabalhos de revisão por BARRETTO $(5,6)$ e DEANE (20) . Podemos, pelo menos tentativamente, considerar como reservatórios silvestres do T. cruสi no Brasil os mamíferos incluídos na relação abaixo, na qual adotamos a sistemática e a nomenclatura de CABRERA (15) .

1. MARSUPIALIA: Monodelphis domestica domestica (Wagner, 1842), Marmosa (Thylamys) agilis agilis (Burmeister, 1854), Philander opossum opossum (Linnaeus, 1758), Metachirus nudicaudatus myosurus (Temminck, 1825), Lutreolina crassicaudata crassicaudata (Desmarest,
1804), Didelphis azarae azarae (Temminck, 1825), Didelphis marsupialis aurita (Wied, 1826).

2. CHIROPTERA: Eumops abrasus (Temminck, 1827) .

3. PRIMATES: Cebus apella versutus (Elliot, 1910), Saimiri sciureus sciureus (Linnaeus, 1758) e Callithrix jacchus (Linnaeus, 1758).

4. EDENTATA: Tamandua tetradactyla tetradactyla (Linnaeus, 1758), Euphractus sexcinctus flavimqnus (Desmarest, 1804), Cabassous unicinctus (Linnaeus, 1758) e Dasypus novemcinctus novemcinctus (Linnaeus, 1758).

5. CARNIVORA: Eira barbara barbara (Linnaeus, 1758) e Eira barbara poliocephala (Traill, 1821).

6. RODENTIA: Oryzomys (Oryzomys) subflavus (Wagner, 1842), Nectomys (Nectomys) squamipes amazonicus (Hershkovitz, 1844), Akodon arviculoides cursor (Winge, 1888), Cercomys curicularius laurentius (Thomas, 1903), Cavia aperea aperea (Erxleben, 1777), Galea spixii spixii (Wagner, 1831), Dasyprocta azarae azarae (Lichtenstein, 1823), e Coendou insidiosus insidiosus (Kuhl, 1820). Entre os roedores poderíamos incluir os ratos comensais, $R a t$ tus norvegicus (Berkenhout, 1769) e Rattus rattus (Linnaeus, 1758) que, embora sejam considerados animais domiciliados ou sinantrópicos, cm freqüência são encontrados em ecótopos naturais.

Quanto aos vectores, de um total de cêrca de 90 espécies de triatomíneos, em sua imensa maioria exclusivas do Continente Americano, 38 espécies, pertencentes a oito gêneros, ocorrem no Brasil.

Como se sabe, os triatomíneos são insetos primitivamente silvestres. Alguns adaptaram-se secundàriamente aos ecótopos artificiais, mas a maioria conserva seus hábitos primitivos, vivendo em nichos ou ecótopos nat rrais. Assim, o Psammolestes coreodes e o Psammolestes tertius habitam ninhos de pássaros, principalmente os grandes ninhos construídos de gravetos pelo Anumbius annumbi e pelo Phacellodomus rufifrons; a Cavernicola pilosa vive em abrigos de morcegos, o Belminus rugulosus em ninhos de preguiças, o Panstrongyius geniculatus em tocas de tatus, o Triatoma neotomae em ninhos de roedores, o Rhodnius neglectus no tôpo de palmeiras etc. 
Mesmo aquelas espécies consideradas como domiciliadas ou sinantrópicas, conservam, pelo menos em certas áreas, hábitos silvestres, sendo encontradas em diversos tipos de ecótopos naturais. É o que acontece, por exemplo, com o Triatoma sordida, o Panstrongylus megistus e, mesmo com o Rhodnius prolixus e o Triatoma infestans, estas duas últimas até há pouco tidas como estritamente domiciliadas, mas que, como se sabe hoje, podem ser encontradas em múltiplos criadouros naturais, segundo mostram as investigações de GAMBOA $(25,26)$, na Venezuela, e de BARRETTO, SIQUEIRA E CORREA (10) e BARRETTO e FERRIOLLI (9), no Estado de São Paulo. Parece que a única espécie verdadeiramente sinantrópica é o cosmopolita Triatoma rubrofasciata, que vive principalmente em cidades portuárias.

Por outro lado, algumas espécies de triatomíneos parecem ter preferência marcada por certos hospedeiros, como se poderia deduzir da associação constante entre êles, como sucede por exemplo, nos casos já mencionados da Cavernicola pilosa e os morcégos, o Belminus rugulosus e as preguiças, - Panstrongylus geniculatus e os tatus. Mas outras espécies são euritróficas, vivendo indiferentemente do sangue de vários vertebrados, ou se têm um hospedeiro preferencial, podem, na ausência dêste, sugar sangue de outros animais. E o que demonstram as investigações realizadas por FREITAS, SIQUEIRA e FERREIRA (24) e por BARRETTO, SIQUEIRA e FREITAS (14), BARRETTO, SIQUEIRA, FERRIOLLI e CAVALHEIRO (12) e BARRETTO e CARVALHEIRO (8) sôbre triatomíneos encontrados em ecótopos silvestres, procurando determinar-lhes as preferências alimentares com auxílio da reação de precipitina.

Muitas são as espécies de triatomíneos extradomiciliários encontrados naturalmente infectados por tripanossomos idênticos ou semelhantes ao $T$. cruzi no Brasil: Panstrongylus megistus, Panstrongylus geniculatus, Panstrongylus lignarius, Panstrongylus lutzi, Triatoma infestans, Triatoma brasiliensis, Triatoma sordida, Triatoma rubrovaria, Triatoma maculata, Triatoma vitticeps, Rhodnius domesticus, Rhodnius nasutus, Rhodnius neglectus e Parabelminus carioca. É muito possivel e prová- vel que pesquisas mais exaustivas venham demonstrar a presença, em ecótopos silvestres, da infecção natural de outras espécies que ocorrem entre nós mas que, até agora, só foram encontradas infectadas em outros paises, como o Panstrongylus rufotuberculatus, o Neotriatoma circummaculata, o Rhodnius prolixus, o Rhodnius pictipes, o Eratyrus mucronatus e a Cavernicola pilosa.

É provável ainda que se venha a demonstrar a infecção natural de outras espécies brasileiras silvestres que até agora não foram encontradas infectadas: Triatoma arthurneivai, Triatoma costalimai, Triatoma gomesi, Triatoma mattogrossensis, Triatoma melanocephala, Triatoma oliveirai, Triatoma petrochi, Triatoma tibiomacula. ta, Triatoma williamsi, Triatoma wygodzinskyi, Rhodnius brethesi, Rhodnius robustus, Panstrongylus diasi, Panstrongylus tupynambai, Psammolestes coreodes, Psammolestes tertius e Neotriatoma limai.

O que acabamos de expor explica, à exuberância, o porque de uma multiplicidade e variedade grande de focos naturais da tripanossomose americana.

Estudaremos, a seguir, os principais focos que temos tido a oportunidade de descobrir e caracterizar na região nordeste do Estado de São Paulo e áreas limítrofes do Estado de Minas Gerais.

ESTUDO DE ALGUNS FOCOS NATURAIS

\section{CAVIDADES NO SOLO}

A. BURACOS DE TATU - Focos naturais típicos e interessantes são constituídos pelas tocas escavadas por dasipódidas. Embora possam ser encontradas em áreas abertas, as tocas de moradia são construídas de preferência dentro de matas, bosques e campos com vegetação densa. Os buracos freqüentemente vistos em campos limpos e áreas de cultura constituem escavações que os tatus fazem à procura de alimento.

Os focos naturais representados pelos buracos de tatus foram postos em evidência por CHAGAS $(17,18)$ que não só registrou a infecção natural do $D$. novemcinctus novemcinctus, como também encontrou em suas tocas exemplares do $P$. geniculatus naturalmente infectados. 
Parece indiscutivel que os tatus, particularmente a espécie acima referida, constituem bons hospedeiros naturais do $T$. cruzi, visto que sua infecção tem sido assinalada em tôda a América e, pelo menos em certos áreas de nosso País, os índices de infecçāo atingem cifras elevadas.

Embora encontrado em outros habitáculos representados por tocas de animais no solo, como assinalam LENT e MARTINS (30), LENT (29), PIFANO (35), o P. geniculatus tem por ecótopo natural mais típico as locas de tatus e é o responsável pela transmissão do T. cruzi entre êstes mamíferos. Assim por exemplo, PIFANO (35), na Venezuela, tem observado altos índices de infecção entre grande número de exemplares que tem examinado. Recentemente pudemos capturar um lote de $P$. geniculatus em um buraco habitado pelo $D$. novemcinctus, em Corumbá, GO; quatro entre dez ninfas examinadas mostraram-se positivas para $T$. cruzi; três que se achavam infectadas deram reação positiva com sôro anti-tatu.

B. LOCAS DE ROEDORES - À primeira vista poderia parecer justificável a distinção entre tocas escavadas no solo por roedores e as constituídas por cavidades naturais ou artificiais ocupadas por êstes animais. Na prática, porém, tal distinção é difícil, isto porque alguns roedores têm hábitos escavadores especializados, abrigando-se em locas que constroem com suas mãos robustas e dotadas de unhas fortes, como acontece com os "ratos focinhudos", pertencentes ao gênero Oximycterus, da familia Cricetidae, ou com os tuco-tucos, pertencentes ao gênero Ctenomys, da familia Ctenomyidae. Outros são roedores terrícolas por excelência, mas não têm hábitos escavadores muito desenvolvidos, preferindo ocupar tocas ou anfractuosidades naturais ou artificiais preexistente, que alargam ou não; é o que acontece com os "ratos do campo" pertencentes aos gêneros Akodon, Hesperomys ou Calomys, da família Cricetidae, com as preás ou cuins e mocós, pertencentes aos gêneros Cavia, Galea e Kerodon, da Iamília Caviidae, e com as cutias, pertencentes ao gênero $D a$ syprocta, da família Dasyproctidae. Por esta razão, preferimos reunir êstes roedores sob a denominação genérica de terricolas ou cavicolas, e considerar como suas tocas desde os buracos literalmente por êles escavados até as anfractuosidades, fendas ou cavidades naturais ou artificialmente escavadas por outros animais, mas por êles ocupadas.

Poucas são as espécies de roedores terrícolas ou cavícolas até agora encontradas, entre nós, com infecçāo natuíal. Deixando de parte os ratos comensais, apontaremos a cutia, $D$. azarae azarae, as preás, G. spixii spixii e $C$. aperea aperea, e o punaré, $C$. cunicularius laurentius.

Relativamente aos vectores, o $P$. megistus parece desempenhar papel de relêvo na transmissão do $T$. cruzi entìe os roedores, ao menos na área em que trabalhamos. Assim, em ninhos de roedores terrícolas, BARRETTO, SIQUEIRA e FREITAS (14) capturaram 14 exemplares dêste triatomíneo, três dos quais estavam infectados. SOTO, SOTO e BARRETTO (37), em tocas de cutia no município de Morro Agudo, coletaram 36 ninfas de $F$. megistus, 15 das quais estavam infectadas; as reaçōes de precipitina deram resultados positivos com sôro anti-rato em 11 casos. Observações inéditas que possuímos mostram que, entre os exemplares desta espécie capturados em locas no solo, 28 reagiram positivamente com sôro anti-rato $e$, entre êles, 18 estavam infectados.

Outro vector parece ser o $T$. sordida. Em tocas de preás, no município de Ribeirão Prêto, FERRIOLLI e BARRETTO (23) capturaram 21 exemplares dêste triatomíneo e observaram a infecção em quatro; as reaçōes de precipitina deram resultados positivos com sôro anti-rato em seis casos. Dados inéditos que possuímos revelam que entre exemplares capturados em locas várias no solo, 22 deram resultados positivos com sôro anti-rato e, entre êles; seis se achavam infectados.

Ainda com referência a roedores terricolas e rupícolas, outro provável foco natural seria constituído por locas de mocós, $K$. ruprestis. Embora a infecção natural dêste animal não haja sido assinalada, em suas tocas encontra-se, com muita freqüência, o $T$. brasiliensis que, na região de Paulo Afonso, no Rio São Francisco, apresenta índices de infecção superiores a $50 \%$, segundo comunicação pessoal do Professor Air Barretto 
C. TOCAS DE MARSUPIAIS - Embora sejam muito mais encontradiços em outios habitáculos, os gambás, especialmente o $D$. azarae azarae, às vêzes constroem seus ninhos ou procuram abrigo em cavidades naturais do solo ou em locas construídas no solo por outros animais. O gambá-marta ou cuica, $L$. crassicaudata crassicaudata, outro bom hcspedeiro do $T$. cruzi, também ocupa êste tipo de ecótopo

Por out o lado, sem ser escavadoras, certas cuícas mal adaptadas à vida arborícola, como a $M$. domestica, cuja infecção natural já foi assinalada, constroem seus ninhos em cavidades do solo ou simplesmente as ocupam sem mesmo construir ninhos.

Quanto aos vectores parece que o $P$. megistus tem papel importante. Com efeito, BARRETTO, SIQUEIRA E FREITAS (14) capturaram 17 exemplares dêste triatomíneo em ninhos de gambás em locas de pedras e verificaram a infecção de cinco exemplares. BARRETTO, SIQUEIRA, FERRIOLLI e CARVALHEIRO (13) confirmam as observações anteriores, registrando indice de infecçâo de $28,6 \%$ entre exemplares capturados em ninho de gambá no solo. Resultados inéditos que possuímos indicam que entre os espécimes de $P$. megistus capturados em locas, algumas habitadas por gambás ou gambás-martas, 30 continham sangue de marsupial no tubo digestivo e, entre êles, 14 estavam infectacios.

Outro bom vector é o $T$. sordida. Com efeito, BARRETTO, SIQUEIRA, FERRIOLLI e CARVALHEIRO (13) obtiveram um indice de infecção de $21,4 \%$ entre exemplares dêste triatomíneo capturado ${ }_{S}$ em ninho de gambá no solo. Dados inéditos que possuímos confirmam esta verificação e mostram que, entre os exemplares de $T$. sordida capturados em locas no solo, 20 reagiram positivamente com sôro anti-gambá; entre êles nove estavam infectados.

D. ABRIGOS DE MORCEGOS - Numerosas são as espécies cavícolas de morcegos, algumas das quais têm sido encontradas com infecção natural por flagelados semelhantes ao $T$. cruzi. Sendo o problema dos tripanossomos de quirópteros assunto controverso, abstemo-nos de tecer maiores comentários a respeito dos possiveis focos naturais representados por locas e cavernas habitadas po: morcegos.

\section{2. ÁRVORES}

A. TOCAS DE MARSUPIAIS - Várias sāo as espécies de marsupiais arborícolas cuja infecção natural já foi assinalada. Embora possam procurar abrigo ou mesmo nidificar em outrcs habitáculos, os gambás sāo, pelo menos entre nós, os mais freqüentes habitantes de ocos ou cavidades no tronco de árvores e de espaços entre raizes ou sob estas. Isto acontece sobretudo com - D. marsupialis aurita, espécie mais silvestre que o $D$. azarae azarae, preferindo geralmente matas ou vegetação densa, próximas de cursos d'água ou lugares úmidos. Os habitáculos apresentam os mais variados aspectos e podem esta: localizados dentro de matas ou bosques ou em árvores isoladas situadas em áreas abertas.

Ainda que possa abrigar-se em cavidades naturais do solo e outros habitáculos, o gambá-marta, L. crassicaudata crassicaudata, com freqüência é encontrado em ocos de árvore. Por outro lado, diversas cuícas do gênero Marmosa, como a $M$. agilis agilis e a $M$. cinerea cinerea, são tipicamente arborícolas. Também habitam ocos de árvores próximos do solo certas cuícas que, menos adaptadas à vida arbórea, preferem cavidades no solo, como a $M$. domestica. Embora geralmente construa seu ninho em tufos de vegetação, o $P$. opossum opossum pode ser encontrado em ocos de árvores.

Relativamente aos vectores, o $P$. megistus é o triatomíneo mais comumente associado aos marsupiais. LEAL, FERREIRA e MARTINS (28), na Ilha de Santa Catarina, foram os primeiros a chamar a atenção para a freqüência de ninhos de gambás em troncos de árvores, ninhos êstes infestados pelo triatomíneo em $32 \%$ dos casos. Por outro lado, verificaram um índice de infecção de $100 \%$ dos triatomíneos.

Com o uso das reações de precipitina FREITAS, SIQUEIRA e FERREIRA (24) identificaram sangue de gambá em uma ninfa de $P$. megistus capturada em tronco de árvore onde se abrigava um gambá. BARRETTO, SIQUEIRA e FREITAS (14), em ninhos de gambás localizados em ocos de árvore, capturaram 122 exemplares; entre 118 examinados registraram a infecção de 49 , o que dá um índice de $41,5 \%$. Mais recentemente, BARRETTO, SIQUEIRA, FERRIOLLI e CARVALHEIRO (13), em Ribeirão Prêto, entre exemplares de $P . m^{e_{-}}$ 
gistus capturados em ocos de árvores onde foram encontrados gambás e cuícas, observaram um índice de infecção de $26,3 \%$. Entre 24 exemplares que reagiram positivamente nas provas de precipitina, 11 continham sangue de marsupial em seu tubo digestivo. Resultados semelhantes foram obtidos por BARRETTO e CARVALHEIRO (8) em Uberaba. Para exemplares capturados em ocos de árvores, onde em geral havia ninhos de gambás, obtiveram índice de infecção de 25,6\%; entre 11 reagentes nas provas de precipitina, sete haviam sugado sangue de gambá.

Observaçōes não publicadas que possuimos confirmam a intima associação entre o $P$. megistus e os marsupiais, principalmente gambás, em ocos de árvores. Com efeito, dos exemplares examinados, 210 reagiram positivamente com sôro antigambá e, entre êles, 113 se achavam infectados.

Outra espécie freqüente em troncos de árvore é o $T$. sordida. Sua presença foi aí assinalada por CORREA e FERREIRA (19) e por FREITAS, SIQUEIRA e FERREIRA (24). Investigaçōes de BARRETTO, SIQUEIRA, FERRIOLLI e CARVALHEIRO (13) em Ribeirão Prêto revelaram um indice de infecção de $14,5 \%$ entre os exemplares capturados em ocos de árvores onde, como dissemos, foram encontrados gambás e cuícas; as reações de precipitina deram resultados positivos em 21 exemplares, entre os quais 12 para sangue de marsupial. Em Uberaba, BARRETTO e CARVALHEIRO (8) registraram índice de infecção de $19,5 \%$ entre os exemplares de $T$. Sordida capturados em ocos de árvores, onde se abrigavam gambás. Entre 12 triatomíneos que reagiram positivamente nas provas de precipitina, seis o fizeram com sôro antigambá .

Dados inéditos que possuimos confirmam e ampliam estas observações sôbre relações entre o $T$. sordida e os marsupiais. Dos exemplares capturados em ocos de árvore, 188 deram resultados positivos com sôro antigambá e entre êles 90 se achavam infectados.

Finalmente as pesquisas de BARRETTO, SIQUEIRA A CORREA (10) e BARRETTO e FERRIOLLI (9) revelaram a presença do $T$. infestans com infecção natural em ocos de árvores com ninhos de gambás; alguns exemplares reagiram positivamente com sô- ro precipitante antigambá. Dados inéditos que possuimos confirmam e ampliam estas observações, mostrando que, de um total de 56 exemplares com sangue no tubo digestivo, 17 reagiram com sôro antigambá e, entre êles, oito estavam infectados.

B. NINHOS DE ROEDORES - Inúmeras são as espécies de roedores muito bem adaptadas à vida arbórea e que por isto mesmo são genèricamiente denominadas "ratos arborícolas".

Deixando de lado os típicos e agilíssimos serelepes ou caxinguelês, cuja infecção ainda não foi assinalada entre nós, embora haja sido em outros países, referiremos os ratos arborícolas da família Cricetidae e pertencentes principalmente aos gêneros Rhipidomys, Thomasomys e Oryzomys. A infecção natural do $O$. subflavus já foi assinalada, como vimos. Outros roedores que podem ser considerados como arborícolas são os ouriços, havendo a infecção de algumas espécies sido assinalada. Entre nós o C. insidiosus insidiosus já foi encontrado com infecção natural.

Ratos comensais, principalmente o Rattus rattus que com freqüência são encontrados em ecótopos silvestes representados por ocos de árvores, já têm sido encontrados naturalmente infectados (22)

Como vectores naturais do $T$. cruzi entre os roedores arborícolas destacam-se o $P$. megistus e o $T$. sordida. Com efeito, em ninhos de roedores em ocos de árvore BARRETTO, SIQUEIRA e FREITAS (14) capt'xraram 50 exemplares de $P$. megistus, entre os quais registraram índice de infecção de $14,6 \%$. Altos índices de infecção do $P$. megistus foram observados por BARRETTO, SIQUEIRA, FERRIOLLI e CARVALHEIRO (13) em Ribeirão Prêto e por BARRETTO e CARVALHEIRO (8) em Uberaba, entre triatomíneos capturados em ocos de árvore. Em Ribeirão Prêto, entre 24 exemplares que continham sangue no tubo digestivo, cinco deram resultados positivos com sôro anti-rato; em Uberaba, entre 11 reagentes, um deu resultado positivo para sangue de rato. SIQUEIRA, FERRIOLLI e BARRETTO (35), em ocos e anfractuosidades de árvores situadas na sebe em que foi apanhado um ouriço infectado, capturaram 19 exemplares de $P$. megistus, quatrc dos quais estavam infectados; doi $i_{S}$ exemplares infectados reagiram positivamente 
com sôro anti-rato. Resultados inéditos que possuimos confirmam e ampliam êstes dados sôbre as relações entre o $P$. megisins e os roedores em ocos de árvores. De fato entre os exemplares examinados 82 deram reaçóes positivas com sôro antirato; entre êstes 30 estavam infectados.

Quanto ao $T$. sordida, BARRETTO, SIQUEIRA, FERRIOLLI e CARVALHEIRO (13) em Ribeirão Prêto observaram cinco exemplares com reação positiva com sôro anti-rato, entre 21 que continham sangue no tubo digestivo. Em Uberaba, BARRET TO e CARVALHEIRO (8) identificaram sangue de rato em dois entre 12 que deram resultados positivos nas reações de precipitina. Dados inéditos que possuímos mostram que entre triatomíneos capturados em ocos e anfractuosidades de árvores, muitos com ninhos de roedores, 190 deram resultados positivos com sôro anti-rato; entre êstes 90 se encontravam infectados.

Um outro vector natural do $T$. cruzi entre roedores arborícolas é o $T$. infestans. Embora relativamente pequeno número de exemplares tenha sido até agora obtido, verifica-se que, entre os exemplares que até agora pudemos examinar, sete reagiram po. sitivamente com sôro anti-rato, e, entre êles, cinco estavam infectados.

C. ABRIGOS DE CARNÍVOROS - Di.. versos carnivoros, como por exemplo o quati, $N$. solitaria solitaria, e a irara, $E$. barbara barbara, cuja infecção natural já foi assinalada entre nós, com muita fre. qüência escondem-se em ocos de árvores ou nêles se abrigam temporàriamente durante a procriação.

Pouco se sabe ainda a respeito da extersão da enzootia entre carnivoros silvestres no Brasil, em virtude do pequeno número de exemplares até agora examinados. Mas é possivel que, à semelhança do que ocorre em outros países, pelo menos algumas espécies constituam bons hospedeiros.

O encontro de alguns exemplares de $P$. megistus e $T$. sordida em ocos de árvore, exemplares que reagem positivamente com soros precipitantes anticão e antigato, pode indicar que êstes triatomíneos se alimentam em carnivoros silvestres. Aliás alguns triatomíneos nestas condições se mostram infectados pelo T. cruzi (8).

\section{ABRIGOS DE MORCEGOS - Várias} são as espécies de morcegos que se abrigam em ocos de árvores, algumas das quais têm sido encontradas com infecçāo natural por diversos autores.

Aliás, temos capturado em ocos de árvore muitos exemplares de $P$. megistus e $T$. sordiaja com sangue de morcêgo no tubo digestivo e vários se têm mostrado infectados. Mas o fato de termos até agora encontrado um só exemplar do morcêgo $E$. abrasus, infectado pelo $T$. cruzi, aliado às uuvidas que existem sôbre a identificaçã dos flagelados de quirópteros, impede-nos de dar maior importância aos eventuais focos naturais representados pelos ocos dt árvores habitados por morcêgo.

3. GRAVATÁs - Parece que as únicas observações sôbre êstes criadouros st devam a LEAL, FERREIRA e MARTINS (28) que encontraram ninhos de gambá, $D$. azarae azarae, construídos em touceiras de gravatás terrestres. Nestes ninhos capturaram exemplares de $P$. megistus que se mostraram infectados em $100 \%$ dos casos.

Por outro lado, em ninhos de rato, Echimys dasythrix (Hensel, 1872), também localizados em touceiras de gravatás, assinalaram a presença do $P$. megistus e do $R$. domesticus, com indices de infecção de $\mathbf{2 2 , 1 \%}$ e $\mathbf{7 8 , 9 \%}$ respectivamente.

Em várias localidades tivemos a ocasião de realizar pesquisas de triatomíneos em touceiras de uma bromeliácea relativamente comum, a Bromelia fastuosa, vulgarmente conhecida como gravatá, gravatáđe-gancho, gravatá-de-rapôsa, caravatá, carauatá, graguatá etc. É uma planta terrestre, quase acaule, com longas fôlhas que chegam a medir até dois metros de comprimento; desenvolve-se espontâneamente e vegeta socialmente em qualquer tipo de solo, chegando em algumas áreas a constituir verdadeira praga.

Nas touceiras de gravatás muitas vêzes encontramos gambás, especialmente o $D$. azarae azarae, que ali constroem seus ninhos de fôlhas sêcas. Ninhos de pequenos roedores, principalmente $E$. nigrispinus, assim como de ratos comensais, são também ali observados.

Observações inéditas que possuimos mostram que o $P$. megistus e o $T$. sordida sāo encontrados nestes ecótopos, onde pudemos registrar indices de infecção de 
$21,5 \%$ para o primeiro e $8,20 \%$ para o segundo. Entre os exemplares de $P$. megis$t u_{s}, 61$ reagiram positivamente com sôrs antigambá, e, entre êstes, 16 estavam infectados; 20 reagiram positivamente com sôro anti-:ato e, entre êstes, 10 se achavam infectados. Entre exemplares de $T$. Sordi$d a, 14$ reagiram com sôro anti-rato e oito, entre êles, se achavam infectados; sete deram reaçōes positivas com sôro antigambá e um, entre êles, estava infectado.

\section{TUFOS DE VEGETAÇÃO}

Entre os animais que já foram encontrados naturalmente infectados e que, com freqüência, constroem seus ninhos de paIha ou capim em meio a tufos de vegetação herbácea, principalmente em lugares úmidos, citaremos a $L$. crassicaudata crassicaudata.

Dos roedores até agora encontrados infectados, duas espécies constróem seus ninhos em tufos de vegetação: o rato-docampo, $A$. arviculoides cursor, e o ratod'água, $N$. squamipes squamipes, com a subespécie $N$. a. amazonicus. O primeiro, embora possa aproveitar ocos e anfractuosidades na base de árvores ou cavidades naturais do solo, geralmente constroi seus ninhos com capim sêco, entre a vegetação densa, geralmente touceiras de gramíneas altas, em áreas de campo, em bosques e na orla de matas. O $N$. squamipes prefere áreas mais úmidas e constroi seu ninho com capim, prêso à vegetação vertical, geralmente a uma certa altura do solo.

Em pesquisas de triatomíneos em ninhos de cuícas e ratos situados em tufos de vegetaçāo, encontramos algumas dezenas de exemplares de $P$. megistus e $T$. sordida, entre os quais observamos índices de infecção de $14,3 \%$ e $6,2 \%$ respectivamente (dados inéditos).

A despeito de alguns exemplares haverem sido encontrados em ninhos de $L$. crassicaudata crassicaudata não obtivemos reações positivas com sôro precipitante antigambá. Quat:o exemplares de $P$. megistus, entre os quais dois infectados, e 19 exemplares de $T$. sordida, entre os quais quatro infectados, reagiram positivamente com sôro anti-rato.

\section{PITEIRAS.}

Um dos ecótopos interessantes, se bem que nāo muito freqüente, é constituido por plantas amarilidáceas pertencentes à espécie Fourcroya gigantea, vulgarmente conhecida como piteira. Trata-se de uma planta encontrada em vários tipos de solo, vegetando bem em várias altitudes, sempre em campos ou formações mais ou menos abertas. Quando completamente desenvolvida, suas fôlhas alongadas, subuladas e com mais de dois metros de comprimento, formam um tufo verticilado de cujo centro sai gigantesca inflorescência com a forma de um candelabro.

Nos espaços situados entre grupos de plantas, ou na base das folhas verticiladas näo raro encontramos ninhos ou abrigos de marsupiais, principalmente gambás, e de ratos. Entre os detritos ali acumulados, com relativa freqüência encontramos o P. megistus e o T. sordida; esporàdicamente ali ocorre o $R$. neglectus.

BARRETTO, SIQUEIRA e FREITAS (14), entre exemplares de $P$. megistus capturados em piteiras, observaram indice global de infecção de $\mathbf{2 5 , 5} \%$. A maioria dêstes triatomíneos foi encontrada em ninhos de gambás e ratos e alguns reagiram positivamente com soros antigambá e anti-rato. Mais recentemente BARRETTO, SIQUEIRA, FERRIOLLI e CARVALHEIRO (13) capturaram algumas dezenas de exemplares de $P$. megistus e $T$. sordida em piteiras, registrando índices de infecção de $45,0 \%$ e $18,7 \%$, respectivamente, para as duas espécies. Alguns exemplares continham sangue de marsupial e de rato no tubo digestivo. Raros exemplares de $R$. neglectus encontrados mostraram-se negativos.

Dados inéditos que possuímos indicam que, entre triatomíneos capturajos em piteiras, observamos índice global de infecção de 11,1\%. Os indices de infecção especificos foram: $P$. megistus $-24,2 \%, T$. sordida - 6,7\% e $R$. neglectus - 4,6\%. A maioria dos exemplares de $P$. megistus que deram reações de precipitina positivas continha sangue de marsupial e rato no seu tubo digestivo; entre 10 positivos para sangue de gambá, cinco estavam infectados, e, entre sete positivos para sangue de rato, três mostravam-se parasitados. A maioria 
dos exemplares de $T$. sordida que continha sangue no tubo digestivo :eagiu com sôro anti-rato e antigambá; entre '3E exemplares com sangue de rato, 12 estavam infectados e entre 12 com sangue de gambá, quatro estavam infectados. Quanto ao $R$. neglectus, capturado em menor número e com menor freqüência, as reações de precipitina deram resultados positivos para sangue de ave, gambá e rato; sòmente entre raros exemplares com sangue de rato no tubo digestivo observamos a infecção natural.

\section{PALMEIRAS.}

De há muito que a presença de alguns triatomíneos, principalmente espécies do gênero Rhodnius, vem sendo assinalada na copa de palmeiras. Investigações mais recentes vieram evidenciar a importância das palmeiras como focos naturais da tripanossomose americana.

De início devemos ressaltar que, entre as múltiplas espécies de palmeiras, três parecem assumir maior importância na área em que trabalhamos, dada a freqüência com que se mostram infectadas: a macaubeira, também chamada macaibeira ou simplesmente macaúba ou macaíba, Acrocomia sclerocarpa, o babaçu ou baguaçu, Orbignya martiana, e o buruti ou miriti, Mauritia vinifera. Também tem importância pela sua freqüência, embora mostre índices de infestação muito menores, o aricuri, ariburi ou bacuri, Scheelea phalerata. Esporàdicamente exemplares de $R$. neglectus têm sido encontrados em duas outras palmeiras, a guariroba, gabiroba ou palmito amargo, Syagrus oleracea, e no coqueiro gerivá ou simplesmente coquinho, Arecas. trum romanzoffianum; por isto, as deixaremos de lado nas presentes considerações.

A Acrocomia sclerocarpa. (erradamente citada como $A$. macrocarpa em nossos trabalhos anteriores) é uma palmeira muito espinhosa, de grande porte e de fôlhas pinatífidas. Muito comum em tôda região em que trabalhamos, vegeta em vários tipos de terrenos e formações florísticas, exceto cerrados. São freqüentes nas matas. Quando da derrubada destas, as palmeiras, via de regra, são respeitadas e continuam a vegetar e a multiplicar-se nos campos artificiais (pastagens) e principalmente em terras de cultura abandonadas, onde constituem grupos às vêzes densos. À medida que a palmeira cresce, as fôlhas mais velhas secam, mas não se destacam. Com o correr do tempo destacam-se primeiro o limbo e depois o peciolo, permanecendo, porém, a bainha ou parte desta, o que dá ao estipe aspecto escamoso. Só nas palmeiras mais velhas, de respeitável altura e diâmetro, os restos da bainha acabam por se desprender, ficando o estipe liso até certa altura. Durante o crescimento da palmeira, a bainha das fôlhas novas vai se resolvendo em fibras que constituem a incúvia.

A Orbignya mariana é palmeira glabra, de alto porte e também de fôlhas pinatíficas que formam uma grande copa frondosa. Vegeta em condições até certo ponto semelhantes àquelas requeridas pelas macaubeiras, mas sua área de distribuição difere. É, como a macaubeira, encontrada tanto em matas de sopés e encostas de serras, como em pastagens ou áreas de cultura e, às vêzes, forma densos e extensos agrupamentos. O crescimento da palmeira é semelhante, mas as fôlhas e suas bainhas conservam-se por mais tempo antes de se destacar do estipe e daí resulta o tamanho da palmeira.

A Mauritia vinifera é uma palmaira glabra, de grande porte e de fôlhas palmadas. Vegeta em terrenos úmidos, brejos e alagadiços, vulgarmente denominados "resfriados", onde formam elegantes grupos. Suas fôlhas, à medida que secam, vão se destacando, de maneira que o estipe é nu.

A Scheelea phalerata é uma palmeira glabra, de altura média e de fôlhas pinatífidas. Vegeta socialmente em lugares planos, preferindo terrenos mais ou menos arenosos, onde forma grandes agrupamentos e, às vêzes, densas matas. Como no caso do babaçu, as fôlhas sêcas e suas bainhas longas conservam-se por mais tempo sem se destacar, de maneira que o estipe, que é relativamente fino, mantem-se todo revestido, exceto na base, no caso das palmeiras mais velhas.

Nas macaubeiras, como já assinalaram FREITAS, SIQUEIRA e FERREIRA (24), com freqüência maior ou menor encontramos ninhos ou abrigo de aves, gambás e morcegos; não é também raro o encontro de ratos arboricolas nestas palmeiras. O 
mesmo acontece com os babaçus, mas suas copas mais frondosas oferecem maior abrigo a aves e mamíferos, como mostraram BARRETTO e CARVALHEIRO (8). Já no caso dos buritis, em virtude da queda mais precoce das fôlhas e respectivas bainhas, há menos abrigo para animais; por outro lado, o fato de estas palmeiras crescerem em alagadiços, torna o acesso de mamíferos trepadores mais difícil. Contudo, encontramos com muita freqüência ninhos de pássaros e abrigos de morcegos na base alargada do pecíolo das grandes fôlhas palmadas, e, nas áreas mais sêcas, podemos encontrar nestas palmeiras alguns marsupiais e roedores arborícolas, como já assinalamos em trabalho anterior (8). Quanto aos aricuris, suas copas frondosas e estipe escamoso oferecem amplo abrigo para aves, gambás, pequenos roedores e morcegos.

Os triatomineos que habitam palmeiras são encontrados entre os detritos acumulados nas bainhas íntegras ou parcialmente destruídas que ficam prêsas ao longo do estipe, no caso da macaubeiras, aricuris e sobretudo babaçus; são, porém, muito mais freqüentes entre as fibras da indúvia e entre os detritos acumulados na axila das fôlhas, isto é, na própria copa das palmeiras, onde, aliás, os ninhos e abrigos de aves e mamíferos são encontrados. No caso dos buritis os triatomíneos só são encontrados entre os detritos acumulados na axila das fôlhas.

A primeira demonstração de que as palmeiras constituem focos naturais da tripanossomose americana se deve a FREITAS, SIQUEIRA e FERREIRA (24), embora êstes autores não houvessem chamado a atenção para o fato. Com efeito, mostraram que a copa das macaubeiras constitui refúgio de gambás e morcegos; nela se encontram triatomíneos que se alimentam naqueles mamíferos, como demonstraram as reações de precipitina, e que, às vêzes, se mostram infectados por tripanossomos semelhantes ao $\boldsymbol{T}$. cruzi. Pena é que não hajam relatado os resultados completos das pesquisas do tripanossomo nos triatominoes, isto é, $R$. neglectus e $T$. sordida. FREITAS, SIQUEIRA e FERREIRA (24) referem ainda o encontro esporádico de triatomíneos em aricuris, guarirobas e coqueiros gerivás.
Posteriormente BARRETTO, SIQUEIRA e CORREA (10) e BARRETTO, SIQUEIRA E FREITAS (14) referem o encontro de alguns exemplares de $T$. infestans e $P$. megistus em macaubeiras, sem, contudo, terem observado a infecção natural dêstes triatomíneos.

Mais recentemente, BARRETTO, SIQUEIRA, FERRIOLLI e CARVALHEIRO (13), em Ribeirão Prêto, assinalam a ocorrência do $T$. sordida e do $R$. neglectus em macaubeiras, com índice de infecção de $16,7 \%$ e $4,4 \%$ respectivamente. As reaçōes de precipitina mostram que ambas as espécies se alimentam com mais freqüência em aves, mas também sugam gambás e morcegos.

Por outro lado, BARRETTO e CARVALHEIRO (8) no Municipio de Uberaba capturaram em macaubeiras, exemplares de $T$. sordida e $R$. neglectus com índices de infecção de $14,4 \%$ e $11,1 \%$ respectivamente; alguns exemplares de $P$. megistus não infectados foram também capturados. $\mathrm{Em}$ buritis coletaram o $R$. neglectus e o $T$. sordida, com índice de infecção de $13,5 \%$ e $12,0 \%$ respectivamente. Finalmente, em babaçus encontraram o $R$. neglectus em abundância, com índice de infecção de.. $30,5 \%$; nêles capturaram também exemplares de $T$. sordida alguns dos quais infectados. As reaçōes de precipitina deram resultados positivos, com maior frequiência com sôro antiave, o que é natural, dado que os pássaros são os animais que mais comumente nidificam nas palmeiras. Mas aquelas reações indicam que, com freqüência, o $R$. neglectus e o $T$. sordida se alimentam em gambás, ratos, morcegos etc.

Dados inéditos que possuimos e que confirmam e ampliam os acima citados, mostram que a copa das palmeiras, principalmente a macaubeira e o babaçu, e secundàriamente o buriti e o aricuri, constituem importantes ecótopos onde convivem mamiferos silvestres e triatomíneos infectados, principalmente o $R$. neglectus e o T. sordida.

\section{CONCLUSÃO}

A existência de focos naturais enzoóticos da infecção tem implicações práticas de grande importância. Êles podem permanecer não reconhecidos, como que dormen- 
tes, por periodos de tempo indefinidos, isto é, enquanto o homem não entra em contato com êles, constituindo aquilo que MAY (32) chama de zonas silenciosas da doença. Mas, como assinala HOARE (27), representam um perigo epidemiológico potencial e, por isto, sua existência e localização devem ser reconhecidas, a fim de se avaliar a periculosidade potencial de áreas a serem penetradas pelo homem em circunstâncias várias, tais como a coloniza- ção, a construção de estradas e outras obras de engenharia, durante operações militares etc. Desde que a periculosidade de tais focos seja reconhecida, êles podem ser evitados ou medidas adequadas podem ser tomadas a fim de proteger os individuos contra a infecção. Por outro lado, o conhecimento dos focos naturais é importante a fim de se julgar da conveniência ou necessidade de sua eliminação nos programas de combate à doença de Chagas.

\section{S U M M A R Y}

After pointing out that American trypanosomiasis is an amphixenose which fits very well the Pavlovsky's doctrine of diseases with natural foci the Author analyses the problem of multiplicity and diversity of such foci, which are due to the great variety of natural mammalian hosts and triatomine vectors. Some of the most common and important types of natural foci observed in the Northeastern Region of the State of São Paulo and nearby localities of the State of Minas Gerais are described; such foci are represented chiefly by soil and rock cavities and cracks, tree holes, anfractuosities and buttresses, bushes, century plants, and palm-tree tops, where $T$. cruzi circulates among wild riammals and triatomines.

\section{BIBLIOGRAFIA}

1. ABDUSSALAM, M. - Significance of ecological studies of wild animal reservoirs of zoonoses. Bull. Wolrd. Health Org., 21: 179-186, 1959.

2. ALENCAR, J. E. - Estudos sôbre a epidemiologia da doença de Chagas no Ceará. III. Região do Baixo Jaguaribe. Rev. Brasil. Malariol. D. Trop., 17: 149-158, 1965.

3. ALENCAR, J E., ALMEIDA, J. O. SHERLOCK, V.R.A., FRANÇA, A.P. \& LEITE, L. - Estudos sôbre a epidemiologia da doença de Chagas no Ceará. II. Novos dados. Rev. Brasil. Malariol. D. Trop., 15: 551-565, 1963.

4. ALENCAR, J.E., PESSOA, E.P., SHERLOCK, V.R.A., TOMÉ, G.S. \& CUNHA, R.V. - Estudos sôbre a epidemiologia da doença de Chagas no Ceará. I. Dados preliminares. Rev. Brasil. Malariol. D. Trop., 14: 201-219, 1962.

5. BARRETTO, M.P. - Reservatórios do Trypanosoma cruai nas Américas. Rev. Brasil. Malariol. D. Trop., 16: ... 527-552, 1964.

6. BARRETTO, M. P. - Tripanossomos semelhantes ao $T$. cruzi em animais silvestres e sua identificação com o agente etiológico da doença de Chagas. Rev. Inst. Med. Trop. São Paulo, 7: 305-315, 1965.

7. BARRETTO, M.P. - Aspectos ecológicos da epidemiologia das doenças transmissíveis, com especial referência às zoonoses. (em publicação).

8. BARRETTO, M.P. \& CARVALHEIRO, J.R. - Estudos sôbre reservatórios e vectores silvestres do Trypanosoma cruzi. XII. Inquérito preliminar sôbre triatomíneos silvestres no Município de Uberaba, MG., Rev. Brasil. Biol., 26: 5-14, 1966.

9. BARRETTO, M.P. \& FERRIOLLI F. F. - Estudos sôbre reservatórios e vetores silvestres do Trypanosoma cruzi. IV. Infecção natural do Triatoma infestans, encontrado em ecótopos silvestres, por tripanossomo semelhante ao $T$. cruzi. Rev. Inst. Med. Trop. São Paulo; 6: 219-224, 1964.

10. BARRETTO. M.P., SIQUEIRA, A.F. \& CORREA, F.M.A. - Estudos sôbre reservatórios e vetores silvestres do Trypanosoma cruzi. I. Encontro do Triatoma infestans (Hemiptera reduvidae) em ecótopos silvestres. Rev. Inst. Med. Trop. São Paulo, 5: 289-293, 1963.

11. BARRETTO, M.P. SIQUEIRA, A.F., CORRÊA, F.M.A., FERRIOLLI F.o. F' \& CARVALHEIRO, J.R. — Estudos sôbre reservatórios e vetores silvestres do Trypanosoma cruzi. VII. Investigações sôbre a infecção natural de gambás por tripanossomos semelhantes ao $T$. cruzi. Rev. Brasil. Biol., 24: 289-300, 1964. 
12. BARRETTO, M.P., SIQUEIRA, A.F. FERRIOLLI F", F. \& CARVALHEIRO, J.R. - Estudos sôbre reservatórios e vectores silvestres do Trypanosoma cruzi. X. Obse:vaçōes sôbre a infecção natural e experimental da cuíca, $L u$ treolina crassicaudata crassicaudata (Desm., 1904) por tripanossomos semelhantes ao $T$. cruzi. Rev. Brasil. Biol., 25: 237-248, 1965.

13. BARRETTO, M.P., SIQUEIRA, A.F FERRIOLLI $F^{\psi}, F$. \& CARVALHEIRO J.R. - Estudos sôbre reservatórios e vectores silvestres do Trypanosoma cruzi. XI. Observações sôbre um foco natural da tripanossomose americana no Município de Ribeirão Prêto, São Paulo. Rev. Inst. Med. Trop. São Paulo, 8: 103-112, 1966.

14. BARRETTO, M.P., SIQUEIRA, A.F. \& FREITAS, J.L.P. - Estudos sôbre reservatórios e vectores silvestres do Trypanosoma cruzi. II. Encontro do Panstrongylus megistus em ecótopos silvestres no Estado de São Paulo ( $\mathrm{He}$ miptera, Reduviidae) . Rev. Inst. Med. Trop. São Paulo, 6: 56-63, 1964.

15. CABRERA, A. - Catálogo de los mamiferos de America del Sur. Rev. Mus. Argent. Ci. Nat. Bernardino Rivadavia, 4: 1-307, 1957, 4: 309-732, 1960

16. CARVALHEIRO, J.R. \& BARRETTO, M.P. - Estudos sôbre reservatórios e vectores silvestres do Trypanosoma cruzi. XIII. Infecção natural do macaco, Cebus apella versutus Elliot, 1910 por tripanossomo semelhante ao $T$. cruzi (em publicação).

17. CHAGAS, C. - Sôbre um trypanosomo do tatú, ratusia novemcincta, transmitido pelo Triatoma geniculata Latr., (1811). Possibilidade de ser o tatú um depositário do Trypanosoma cruzi no mundo exterior (Nota prévia). Brazi1. Med., 26: 305-306, 1912.

18. CHAGAS, C. - Papel do tatu (Tatusia novemcincta) na transmissāo do Trypanosoma cruzi. Rev. Med. Cir. Brazil, 26: 220-223, 1918

19. CORRÊA, R.R. \& FERREIRA, O.A. - Distribuição geográfica, habitats e infecção de Triatoma sordida (Hemiptera, Reduviidae) no Estado de São Paulo. Rev. Inst. Med. Trop. São Paulo, 1: 207-213, 1959

20. DEANE, L.M. - Animal reservoirs or Trypanosoma cruzi in Brazil. Rev. Brasil. Malariol. D. Trop., 16: 27-48, 1964

21. FERRIOLLI FILHO F . \& BARRETTO M.P. - Estudos sôbre roservatórijs e vectores silvestres do Trypanosoma cruzi. VI. Infecção natural do roedor Akodon arviculoides cursor (Winge, 1885) por tripanossomo semelhante ao Trypanosoma cruzi. Rev. Inst. Med. Trop. São Paulo, 7: 72-81, 1965.

22. FERRIOLLI FILHO, F. \& BARRETTO,
M.P. - Estudos sôbre reservatórios e e vectores silvestres do Trypanosoma cruzi. IX. Infecçáa natural do Rattus rattus (Lin., 1758) por tripanossomo semelhante ao $T$. cruzi. Rev. Inst. Med. Trop. São Paulo, 7: 169-179, 1965.

23. FERRIOLLI F. ${ }^{\circ}$. \& BARRETTO, M.P. - Estudos sôbre reservatórios e vectores silvestres do Trypanosoma cruzi. XIV. Infecção natural da piéá, Cavia aperea aperea Erxleben, 1777 por tripanossomo semelhante ao $T$. cruzi (em publicação)

24. FREITAS, J.L.P., SIQUEIRA, A.F. \& FERREIRA, O.A. - Investigacões eni_ Cəmiológicas sôbre triatomíneos de hábitos domésticos e silvestres com auxílio da reação de precipitina. Rev. Inst. Med. Trop. São Paulo, 2: 90-99, 1960 .

25. GAMBOA, C. J. - Comprobación de Rhodnius prolixus extradomésticos. Bol. Inform. Dir. Malariol. Saneam. Amb., 1: 139-142, 1961.

26. GAMBOA, C. J. - Comprobación de Rhodnius prolixus extradomésticos. Venezuela. Bol. Ofic. Sanit. Panamer.. 65: $18-25,1963$

27. HOARE, C. A. - The epidemiological role of animal reservoirs in human leishmaniasis and trypanosomiasis. Vet. Rev. Annot., 1: 62-68, 1955

28. LEAL, H., FERREIRA NETO, J.A. \& MARTINS, C.M. — Dados ecológicos sôbre triatomíneos silvestres na Ilha de Santa Catarina, Brasil. Rev. Inst. M॰d. Trop. São Paulo, 3: 213-220. 1961.

29. LENT, H. - Transmissores da moléstia Ca Chagas no Estado do Rio de Janeiro. Rev. Flum. Med., 7: 3-13; 1942.

30. LENT, H. \& MARTINS, A.V. - Estudos sôbre os triatomíneos do Estado de Minas Gerais, com descrição de uma espécie nova. Rev. Entomol., Rio de Janeiro, 11: 887-886, 1940 .

31. MARTINS, A.V., VERSANI, W . \& TUPINAMBÁ, A.A. - Estudos sôbre a moléstia de Chagas no Estado de Minas Gerais. I. Estudo epidemiológico de um foco da moléstia no municipio de Jaboticatubas. Arch. Inst. Quim. Biol. Est. M. Gerais, 1: 51-61, 1945

32. MAY (1950). In ABDUSSALAM (1959)

33. PAVLOVSKY (1939). In PAVLOVSKY (1960)

34. PAVLOVSKY, E. N. - Natural nidi of transmissive and parasitic diseases in relation to landscape epidemiology. Leningrad, 1960

35. PIFANO, F. - Algunos aspectos de la enfermedad de Chagas en Venezuela. Arch. Venez. Med. Trop. Parasitol. Mfd., 3: 73-99, 1960

39. FUFIRA, A.F.. FERRIOLLI FILHO, F. \& BARRETTO, M.P. - Estudos sōrre zeservatórios e vectores silvestres do Trypanosoma cruzi. XVI. Infecção natural do ouriço, Coendou insidiosus 
insidiosus (Kuhl, 1820) por tripanossomo semelhante ao $T$. cruzi (em pu. blicação) .

37. SOTO-URRIBARRI, R., SOTO, S. T. \& BARRETTO, M.P. - Estudos sôbre reservatórios e vectores silvestres do Trypanosoma cruzi. XV. Infecção natural da cotia, Dasyprocta azarae azarae Licht., 1823 por tripanossomo semelhante ao $T$. cruzi (em publicação).

\section{AGRADECIMENTOS}

Nossos agradecimentos ao Dr. A. Taunay, do. Instituto Adolfo Lutz, de São Paulo e ao Dr. J. Luciolla, da Faculdade de Medicina da Universidade Federal de Minas Gerais.
SPRUE TROPICAL : culturas de virus a par. tir de "swabs" ratais - Os autôres estudam 3 grupos de pacientes, o primeiro (G:upo 1), constituindo-se de 50 pacientes nunca tratados ou sem terapêtica durante os últimos c.nco anos; a idade variou de 15 a 75 anos, sendo 34 de baixo padrāo social e os demals prove. nientes de classes sociais mais favorecidas. $O$ diagnóstico de sprue baseou-se em evidênzias clínicas, como diarréia e perda de pêso, em dados laboratoriais, como go dura fecal e absorção de xilose anorm:is, anemia megaloblástica ou alterações na medula óssez compatíveis com a d.minuição de ácído fólico ou vitamina B12. O segundo (Grupo II), constituído por 10 pacientes com sprue tropical em remissão pelo periodo mínimo de 1 ano, $e$, finalmente, o (Grupo III), contrôle, com 48 individuos em boas condições de saúde, assintomáticos, com a idade mínima de 16 anos.

Obtiveram-se "swabs" retais e orofaringeos no dia da consulta ou durante os três primeiros dias de internação; o soro dos pacientes foi colhido nesta mesma ocasiāo e soro de convalescente, 3 a 6 semanas após; todos os espécimes foram conservados a-70\%. O material foi cultivado em células amnióticas, rim de macaco e células $\mathrm{He}$ p-2 e os tubos de cultura examinados em relação a efeitos citop:to. gênicos. Também camundongos recem-nascidos foram inoculados por via intracerebral para firmar o diagnóstico nos casos suspeitos. As viroses foram identificadas por técnicas de neutralização. No Grupo I evidenciou-se um caso infectado pelo Coxsakie B-3, com aumento significativo do título de anticorpos; um dos pacientes do Grupo II teve também um "swab" retal positivo para Coxsackie B-3 e de um paciente do Grupo III foi isolado Echo 8 .

Estes dados mostram a não relaçāo entre virus e sprue tropical, nāo sendo esta entidade patológica, portanto, de natureza virótica. BAYLESS, T.M., GUARIOLA-ROTGER, A. \& WHEBY, M.S - Gastroenterology, 51 : 32-35, 1966. a manual of tropical medicine Hunter, G.W., Frye, W.W. \& Swartzwelder, J.C - 4' Edição, W.B. Saunders, Filadelfia Londres, 1966 - Este excelente livro foi composto em sua primeira edição para suprir as necessidades de informação das Forças Armadas durante a II Guerra Mundial sôbre a ocorrência de doenças frequientes nas áreas tropicais e subtropicais do mundo. A apresentação concisa porém completa dos mais importantes problemas da Medicina Tropical, em seus aspectos epidemiológicos e clínicos, transformou êste "Manual" em um "Livro texto" da maior importância para aquêles que se dedicam ao estudo das doenças infecciosas e parasitárias, da medicina preventiva, da saúde pública e assuntos correlatos.

A categoria e o renome internacional dos autores em si já recomendam êste livro que reflete a experiência $d a$ tradicional "Tulane University" e da moderna "Louisiana State University" no campo da Medicina Tropical. Com a colaboraçāo de 37 especialistas renomados, Hunter, Frye e Swartzwelder acabam de lan. çar esta p.imorosa 4" Ed.ção, agora comple mentada com uma seleta bibliografia que dá ao livro a feição definitiva de uma obra didá. tica.

Organizado em 12 grupos de assuntos, este livro de menos de 900 páginas de texto, com 76 capítulos e 232 ilustraçōes (8 em côres), nos dá uma das maiores provas do poder de sintese, sem prejuízo da precisão do seu exce. lente conteúdo. Merecem destaque os capítulos referentes aos moluscos e artrópodos de importância médica e o último capítulo, que se refere aos métodos de diagnóstico laboratorial por sua importância prática para o médico "tropi. calista". Finalmente, em apêndice, o liı to traz um excelente resumo epidemiológicn $d: s$ doenças infecciosas e parasitarias que ocorrem nas diversas áreas do mundo. 
INFECÇAO INTESTINAL E DISTÚRBIOS NUTRICIONAIS - Nesta análise da relação entre as infecções intestinais e desnutrição, fazse uma breve apreciação dos antecedentes históricos que levaram à determinação, hoje aceita, dos agentes da diarréia infecciosa.

Quando há interação dêsses agentes com a desnutrição, os dados obtidos das experiências com animais não são suficientes para confirmá-la claramente

No tocante à ação dos agentes patogênicos entéricos nos individuos subnutridos, observada nas infecções naturais, analisam-se três possibilidades : a) que a desnutricão torna o indivíduo mais susceptível às doses usuais de agentes patogênicos entéricos ou mesmo aos de baixa patogenicidade; b) que ao contrário, é o processo da infecção intestinal que contribui consideràvelmente para a desnutrição; e c) que a infecção intestinal coincide apenas por acaso com a desnutrição, se há um aumento da ação infecciosa em conseqüência do estado de subnutrição do paciente.

Os dados publicados sôbre êsses problemas mostram que não há aumento da incídência de agentes patogênicos intestinais conhecidos nos grupos humanos desnutridos. Isso parece indício de que a prevalência da diarréia nesses grupos seja resultado de uma perturbação da capacidade patogênica de sua flora intestinal precipitada pela subnutrição ou por uma dieta desequilibrada. Essa possibilidade não foi ainda suficientemente estudada e certos dados importantes são difíceis de interpretar. Dando-seIhe, porém, a devida atenção, bem como ao mecanismo etiopatogênico da diarréia resultante do desequilíbrio da flora, os fenômenos de hipersensibilidade relacionados com a maior absorção de endotoxinas intestinais parecem suficientes para explicar muitas características clínicas, epidemiológicas e patológicas da diarréia endêmica nas populações subnutridas.

A vista dos dados existentes, não é possivel deixar de tomar em consideração a possibilidade de que as infecçōes entéricas contribuam grandemente para o desenvolvimento do estado de desnutrição, porém os autores o fazem com cautela, uma vez que o fenômeno nāo parece registrar-se com frequência em certas regiões.

Finalmente, parece claro que se processa uma ação sinérgica da desnutrição e das infecções entéricas no sentido de agravar as condições físicas do paciente e aumentar o coeficiente de mortalidade. Assinalam os autores, no entanto, que a desnutriçāo e as infecções in. testinais são ambas prevalentes nos grupos de população pobres, cujos padrões de higiene pessoal e ambiental são baixos ou muito baixos, e que êsse fator, em si, contribui para a falta de resistência e a alta mortalidade. SUASSU. NA, I. \& SUASSUNA, I.R. - Bol. Of. San. Panam., 41: 503-521, 1966.

III CONGRESSO DA SOCIEDADE BRASILEIRA DE MEDICINA TROPICAL - Organizado pelo Prof. Aluizio Prata sob o patrocinio da Sociedade Brasileira de Medicina Tropical, realizou-se em Salvador-Bahia, de 31 de janeiro a 4 de fevereiro do corrente ano, o III Congresso da Sociedade Brasileira de Medicina Tropical.

o referido conclave, que contou com seis sessōes de temas oficiais e com apresentação de cêrca de cento e quarenta temas livres de alto nível, constituiu-se num verdadeiro sucesso científico graças à primorosa organização e ao comparecimento de figuras exponenciais da patologia tropical brasileira e de alguns repre. sentantes de países visinhos, como o Prof.

Juan Puigbó, da Venezuela, Giusepe Greco e Alberto Uriarte, da Argentina, David Benta, E.I. Goldsmith e B.H. Kean, dos EE.UU. e Naim Kent, representante da Organização Mundial de Saúde.

Ao lado das atividades científicas, os participantes do Congresso foram brindados com um majestoso programa social oferecido pela Universidade Federal da Bahia e pelo Exmo. Sr. Governador do Estado.

ELEIÇÃO DA DIRETORIA DA SOCIEDADE BRASILEIRA DE MEDICINA TROPICAL PARA O BIENIO 1967-68 - Em assembléia geral realizada no dia 3 de fevereiro último na cidade de Salvador-Bahia, foi eleita a seguinte Diretoria da Sociedade Brasileira de Medicina Tropical para o biênio 1967-68:

Presidente: Prof. J. Rodrigues da Silva, Vice-Presidente: Prof. Aluízio Prata, Secretário Geral: Dr. J. Rodrigues Coura, Secretário: Dr. Jayme Neves, Tesoureiros: $1^{0}-$ Dr. Dawid Krakowski e $2^{\circ}$ - Dr Léa Camillo. Coura.

Conselho Fiscal: Prof. João Alves Meira, Prof. J. Eduardo de Alencar, Prof. Mauro Pereira Barreto, Prof. Miroslau Constante Baranski e Dr. Wladimir Lobato Paraense.

Comissão de redação: Prof Achilles Scorzelli Junior, Prof. Luigi Bogliolo e Prof. Frederico Simões Barbosa. 